\title{
A Novel Dual-Input Boost-Buck Converter with Coupled Inductors for Distributed Thermoelectric Generation Systems
}

\author{
Junjun Zhang ${ }^{*}$, Hongfei $\mathrm{Wu}^{*}$, Kai Sun ${ }^{\dagger}$, Yan Xing*, and Feng Cao \\ *Jiangsu Key Laboratory of Renewable Energy Generation and Power Conversion, College of Automation \\ Engineering, Nanjing University of Aeronautics and Astronautics, Nanjing, China \\ ${ }^{\dagger}$ State Key Lab of Power Systems, Dept. of Electrical and Engineering, Tsinghua University, Beijing, China
}

\begin{abstract}
A dual-input boost-buck converter with coupled inductors (DIBBC-CI) is proposed as a thermoelectric generator (TEG) power conditioner with a wide input voltage range. The DIBBC-CI is built by cascading two boost cells and a buck cell with shared inverse coupled filter inductors. Low current ripple on both sides of the TEG and the battery are achieved. Reduced size and power losses of the filter inductors are benefited from the DC magnetic flux cancellation in the inductor core, leading to high efficiency and high power density. The operational principle, impact of coupled inductors, and design considerations for the proposed converter are analyzed in detail. Distributed maximum power point tracking, battery charging, and output control are implemented using a competitive logic to ensure seamless switching among operational modes. Both the simulation and experimental results verify the feasibility of the proposed topology and control.
\end{abstract}

Key words: Boost-buck converter, Coupled inductor, Distributed DC power system, Multi-input converter

\section{INTRODUCTION}

Thermoelectric generator (TEG), as a renewable and clean power generator, can directly convert heat energy into electrical energy. Increasing attention has been paid to TEG for recovering waste heat energy from vehicles, DC building, and other distributed DC power systems [1]-[5]. By placing thermoelectric modules (TEMs) around the exhaust pipe, waste heat can be harvested and recycled to power the load or to feed the energy storage element, such as a battery or super-capacitor. The radioisotope-based TEG has also attracted attention in deep-space exploration applications due to its long life span, high reliability, and small size [6].

In large-scale TEG power systems, TEMs are connected in parallel or in series to obtain increased power or voltage, because the output power and voltage of a single TEM is low.

Manuscript received Oct. 27, 2014; accepted Mar. 24, 2015

Recommended for publication by Associate Editor Sangshin Kwak.

${ }^{\dagger}$ Corresponding Author: sun-kai@mail.tsinghua.edu.cn

Tel: +86-010-62796934, Tsinghua University

*Jiangsu Key Laboratory of Renewable Energy Generation and Power Conversion, College of Automation Engineering, Nanjing University of Aeronautics and Astronautics, China
However, mismatches among TEMs are inherent due to temperature distribution imbalance, manufacturing tolerances, and aging; hence, simultaneous maximization of the output power of each TEM by centralized maximum power point tracking (MPPT) control is difficult [7], [8]. An effective method for maximizing the output power of the distributed TEG system is to adopt an independent DC-DC converter for each TEM [3], as shown in Fig. 1(a). With independent control of each individual converter, distributed MPPT (DMPPT) of each TEM can be achieved. In this setup however, the system structure becomes complicated and the cost becomes high. An improved solution is the replacement of these individual converters by a multi-input converter (MIC), as shown in Fig. 1(b). Unlike individual converters, MIC has integrated topology and control, which are beneficial to system-level efficiency and power management.

Meanwhile, the TEM can be considered as a voltage source and an internal resistance connected in series. The open-circuit voltage varies within a wide range when external temperature changes. The TEM is sensitive to the current ripple in that, a large current ripple will affect the output performance of a TEM [1], [2]. For the distributed TEG power 


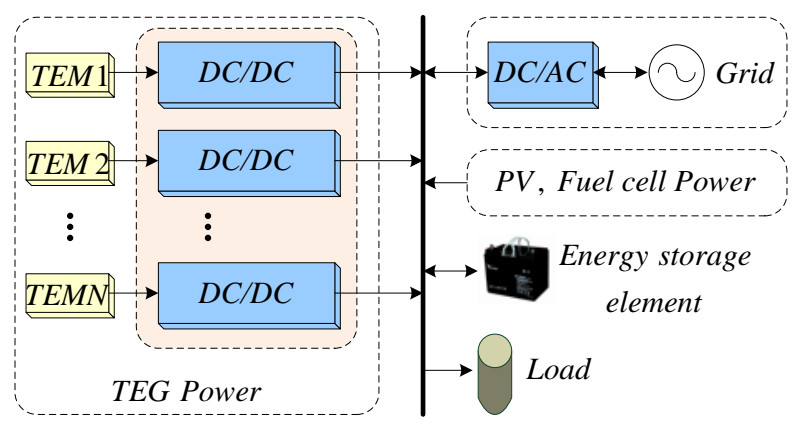

(a)

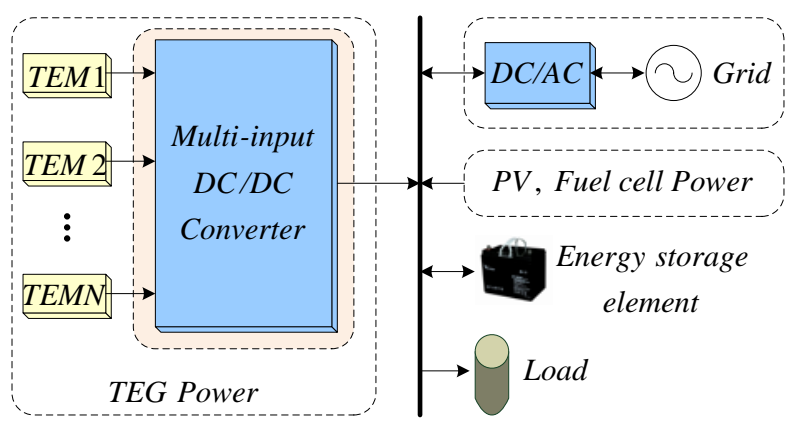

(b)

Fig. 1. Diagram of the distributed TEG power system. (a) Individual converter solution. (b) MIC solution.

system, as that shown in Fig. 1(b), the power converter interfaced to the TEMs, thus, should be a step-up/-down MIC with low current ripple in both input and output sides.

Several step-up/-down MICs for various applications have been proposed in [3], [4], and [9]-[13]. One of these is a MIC topology based on a Cuk converter [3], [4], [9], which can achieve low current ripple in both input and output sides but had opposing input and output polarities. The MIC based on a buck-boost converter, as proposed in [10], also had the polarity problem. In [11], the MIC generated from multiple Sepic cells had the same ground between input and output, but the voltage stresses of the devices were high and the output current was discontinuous. In [13], a novel MIC was derived by the cascading of multiple buck cells by a boost cell, the inductors of which were shared. However, both input and output currents therein were discontinuous. Thus, although these MICs had a simple configuration, simple controls, and could be easily extended, they are not suitable for TEG applications.

The major objective of this paper is to propose a novel step-up/-down dual-input boost-buck converter with coupled inductors (DIBBC-CI) and low input and output current ripple for distributed TEG applications. With the coupled inductors, reduction of the size and power losses of filters can be achieved, leading to high efficiency and high power density in the converter. The topology derivation process, working principle, design consideration, and power management strategy are presented, and the theoretical analysis is verified by both the simulation and experimental results.

\section{DERIVATION OF THE PROPOSED TOPOLOGY}

The cascaded boost-buck converter (BBC), which can achieve step-up/-down conversion with low input and output current ripple, has been applied in TEG power systems, [1], [2]. With the goal of reducing the size of the converter, a BBC with coupled inductors (BBC-CI) was proposed in [14], wherein the inductors of the boost and buck cells were negatively coupled via a common magnetic core. The topologies of the BBC and BBC-CI are shown in Fig. 2.

In the present paper, a multi-input cascaded boost-buck converter (MIBBC) is proposed to satisfy the demand in distributed TEG applications; the input stage is composed of multiple boost switching cells connected in parallel or in series, and the output stage is composed of a buck switching cell. To illustrate the MIBBC (Fig. 3), we take the dual-input parallel approach as an example. Given the cascaded structure, step-up/-down power conversion can be realized. Simultaneously, continuous current in both sides can be achieved because all the filter inductors are placed at the input and output sides of the converter. Thus, the MIBBC is suitable for distributed TEG applications.

However, in the MIBBC topology shown in Fig. 3, the filter inductors of the boost and buck cells are independent, leading to a converter with a large size and volume. To improve power density, we propose that the size of the filter inductors be reduced using coupled inductors. When the input boost inductors and the output buck inductor are coupled, the number of magnetic cores can be lessened, and the size and weight of the converter can then be reduced.

The topology of the proposed MIBBC with coupled inductors (MIBBC-CI) can be derived by coupling the input boost inductors and the output buck inductor of the MIBBC. The primary sides of the coupled inductors are the inductors of the boost cells, whereas the secondary sides are placed in series and serve as the buck inductor. In accordance with the connection of the outputs of the boost switching cells, the proposed MIBBC-CI topologies can be categorized into two parts-parallel and series. Taking the dual-input approach as an example, we illustrate the proposed MIBBC-CI topologies in Fig. 4.

As shown in Fig. 4, the proposed DIBBC-CI is composed of two boost switching cells, denoted as $1 \#$ and $2 \#$, and one buck switching cell. $L_{\text {in1 }}$ and $L_{\text {in2 }}$ are inductors of the boost switching cells, and $L_{01}$ and $L_{02}$ are inductors of the buck switching cell; $L_{\mathrm{in} 1}$ and $L_{\mathrm{in} 2}$ are coupled with $L_{\mathrm{o} 1}$ and $L_{\mathrm{o} 2}$, respectively.

\section{ANALYSIS OF THE PROPOSED TOPOLOGY}

We take the parallel DIBBC-CI shown in Fig. 4(a) for 


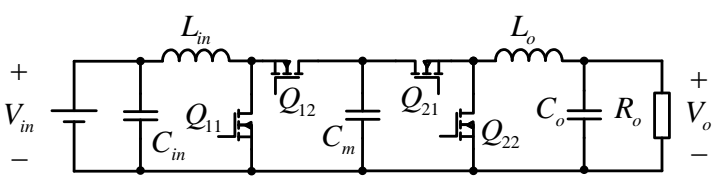

(a)

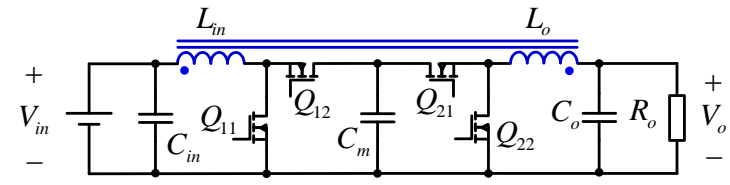

(b)

Fig. 2. Topologies of the BBC. (a) BBC. (b) BBC-CI.

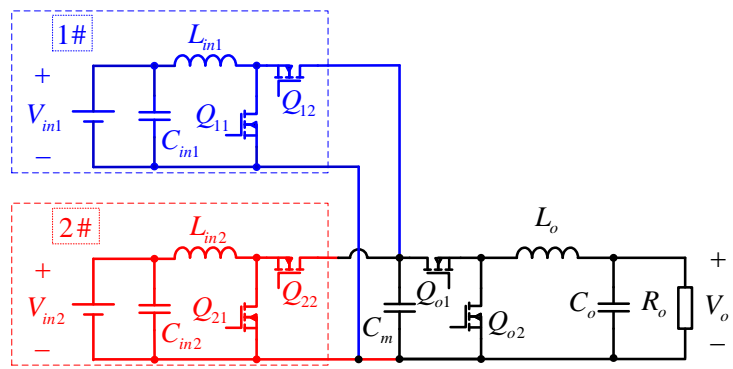

Fig. 3. Topology of the MIBBC.

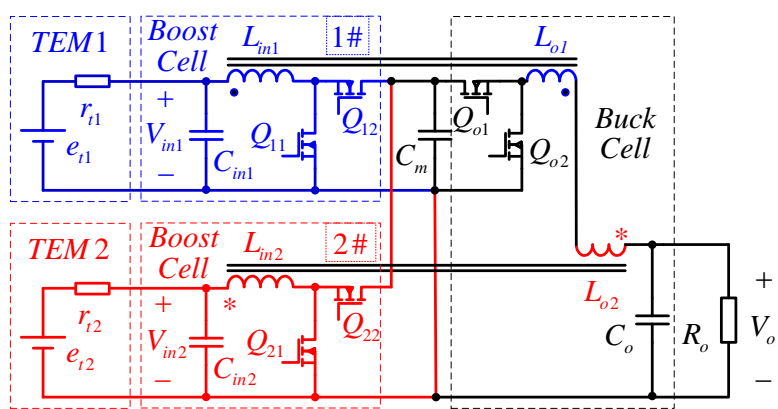

(a)

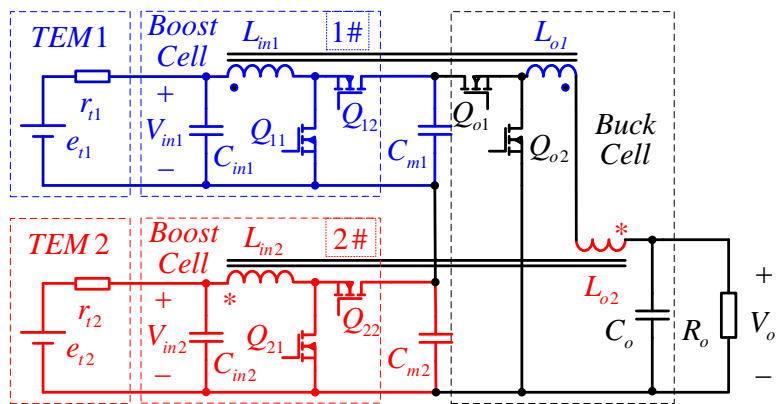

(b)

Fig. 4. Topologies of the proposed MIBBC-CI. (a) Parallel DIBBC-CI. (b) Series DIBBC-CI.

example, which is applied to a dual-channel TEG-sourced system with a battery for its load. As illustrated in Fig. 4(a), $C_{\text {in1 }}, L_{\text {in1 }}, Q_{11}$, and $Q_{12}$ form $1 \#$ boost switching cell to interface with TEM1, whereas $C_{\text {in2 }}, L_{\text {in2 }}, Q_{21}$, and $Q_{22}$ form 2\# boost switching cell to interface with TEM2; $C_{\mathrm{m}}$ is the decoupling capacitor, and $Q_{01}, Q_{02}, L_{01}, L_{02}$, and $C_{0}$ form the buck switching cell to interface with the load.

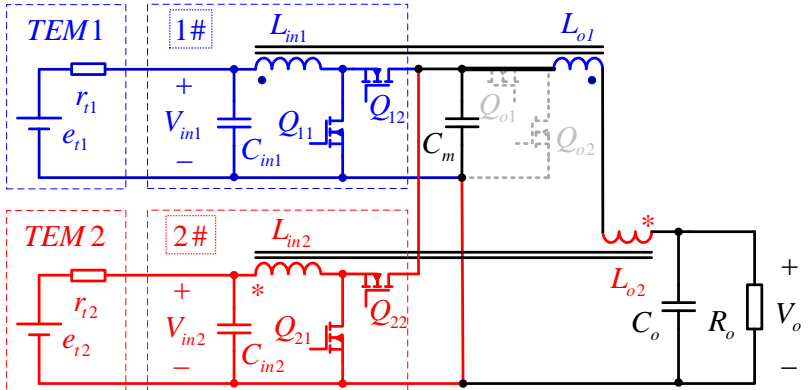

(a)

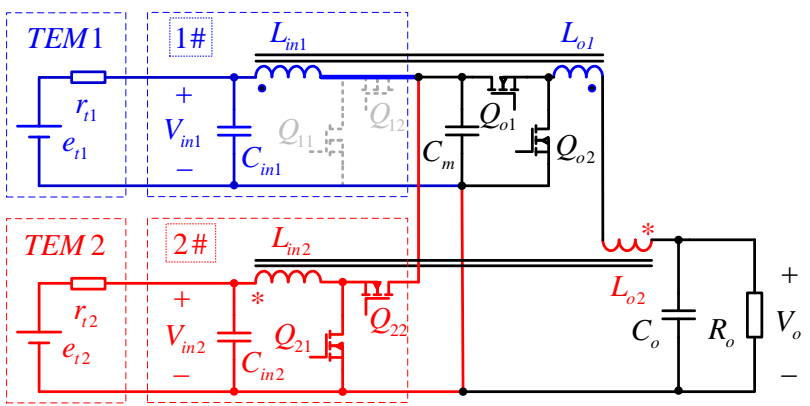

(b)

Fig. 5. Equivalent circuits for the two working modes. (a) Boost\&Boost. (b) Boost\&Buck.

\section{A. Working Modes}

The DIBBC-CI can be regarded as a three-port power system, which can be controlled by only two independent control variables. The switching cell corresponding to the highest port voltage can be maintained in the through state to reduce switching losses, meaning the average voltage of $C_{\mathrm{m}}$ $\left(V_{\mathrm{cm}}\right)$ is always equal to the maximum of input voltages $V_{\mathrm{in} 1}$ and $V_{\text {in2 }}$ and the output voltage $V_{0}$. According to the relationship of $V_{\mathrm{in} 1}, V_{\mathrm{in} 2}$, and $V_{\mathrm{o}}$, DIBBC-CI has two main working modes-Boost\&Boost mode and Boost\&Buck mode.

Boost\&Boost Mode: When $V_{\mathrm{in} 1}<V_{\mathrm{o}}$ and $V_{\mathrm{in} 2}<V_{\mathrm{o}}, Q_{\mathrm{o} 1}$ is kept on and the two boost cells work in step-up state. Shown in Fig. 5(a) is the equivalent circuit of this mode, wherein the output side features a C-L-C type filter. The boost cells are controlled independently to regulate their output voltages according to $V_{\mathrm{o}}$.

Boost\&Buck Mode: When $V_{\text {in } 1}>V_{\text {in2 }}$ and $V_{\text {in } 1}>V_{\mathrm{o}}, Q_{11}$ is kept off, and 2\# boost switching cell works in step-up state while buck switching cell works in step-down state. Shown in Fig. 5(b) is the equivalent circuit of this mode, wherein the input side of $1 \#$ boost switching cell features a C-L-C type input filter. In this mode, the buck switching cell is controlled to regulate output voltage $V_{\mathrm{o}}$, whereas $2 \#$ boost switching cell is controlled to regulate its output voltage according to $V_{\text {in1 }}$.

\section{B. Operational Analysis}

We assume the following: (1) $L_{\mathrm{in} 1}=L_{\mathrm{in} 2}=L_{\mathrm{in}}, L_{\mathrm{o} 1}=L_{\mathrm{o} 2}=L_{\mathrm{o}}$, the coupling coefficient and mutual inductance of $L_{\mathrm{in} 1}\left(L_{\mathrm{in} 2}\right)$ with 


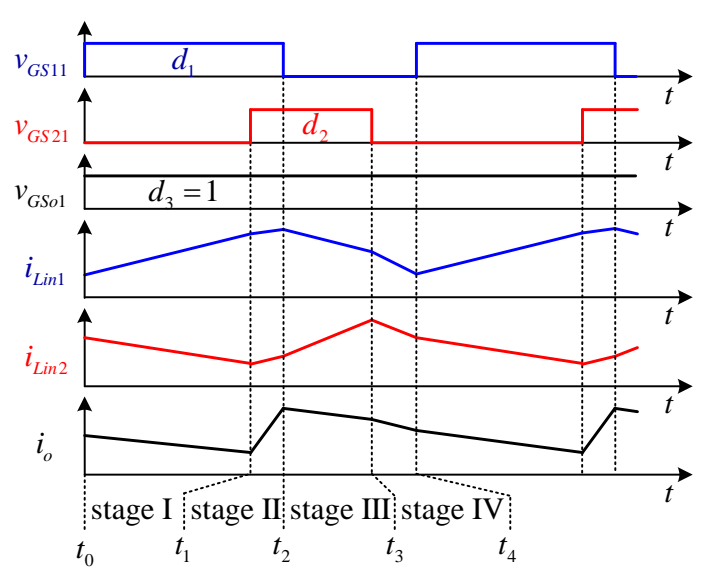

(a)

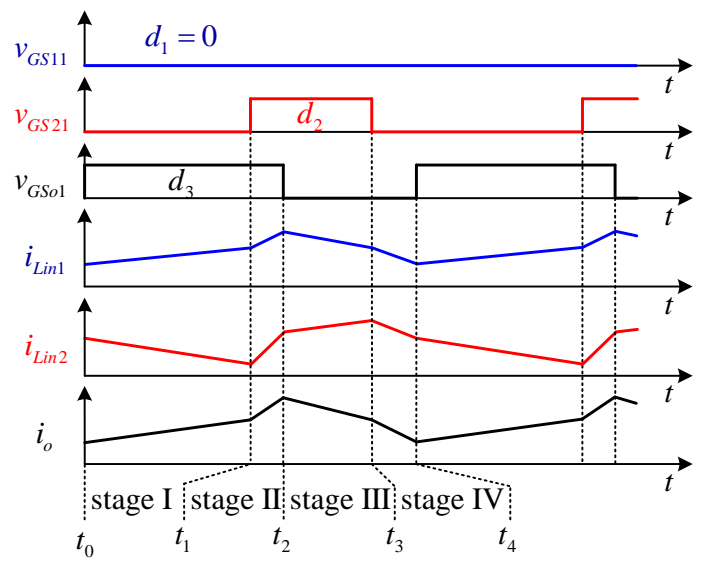

(b)

Fig. 6. Key waveforms of the converter in each of the two working modes. (a) Boost\&Boost mode, 1\#, 2\# boost cells work. (b) Boost\&Buck mode, 2\# boost cell and buck cell work.

$L_{01}\left(L_{02}\right)$ are $k$ and $M$, respectively; (2) All the switches are ideal devices, and $Q_{11}$ and $Q_{21}$ work in interleaved mode with the duty cycles $d_{1}$ and $d_{2}$, respectively, whereas the duty cycle of $Q_{01}$ is $d_{3}$.

1) Boost\&Boost Mode: In Boost\&Boost mode, DIBBC-CI has four switching stages in one period. The key waveforms as based on the assumption that $d_{1}>0.5, d_{2}<0.5, d_{1}-d_{2}<0.5$ are shown in Fig. 6(a), wherein $v_{\mathrm{GS} 11}, v_{\mathrm{GS} 21}$, and $v_{\mathrm{GS} 1}$ are the driving signals of $Q_{11}, Q_{21}$, and $Q_{01}$, and $i_{\mathrm{Lin} 1}, i_{\mathrm{Lin} 2}$, and $i_{\mathrm{Lo}}$ are the currents of $L_{\mathrm{in} 1}, L_{\mathrm{in} 2}$, and $L_{\mathrm{o} 1}\left(L_{\mathrm{o} 2}\right)$.

Stage $I\left(t_{0}-t_{1}\right): Q_{11}$ and $Q_{22}$ are on, $Q_{12}$ and $Q_{21}$ are off, $i_{\text {Lin } 1}$ increases, $i_{\text {Lin2 }}$ and $i_{\text {Lo }}$ decreases, and

$$
\left\{\begin{array}{l}
\frac{d i_{L i n 1}}{d t}=\frac{V_{i n 1}}{L_{i n}\left(1-k^{2}\right)}+\frac{\left(V_{i n 2}-V_{i n 1}-V_{o}\right) k^{2}}{2 L_{i n}\left(1-k^{2}\right)} \\
\frac{d i_{L i n 2}}{d t}=\frac{\left(V_{i n 2}-V_{o}\right)}{L_{i n}\left(1-k^{2}\right)}+\frac{\left(V_{i n 1}-V_{i n 2}+V_{o}\right) k^{2}}{2 L_{i n}\left(1-k^{2}\right)} \\
\frac{d i_{L o}}{d t}=\frac{\left(V_{i n 1}+V_{i n 2}-V_{o}\right) k^{2}}{2 M\left(1-k^{2}\right)}
\end{array}\right.
$$

Stage II $\left(\boldsymbol{t}_{1}-\boldsymbol{t}_{2}\right): Q_{11}$ and $Q_{21}$ are on, $Q_{12}$ and $Q_{22}$ are off, $i_{\text {Lin1 } 1}$, $i_{\text {Lin2 }}$, and $i_{\text {Lo }}$ increase, and
TABLE I

Switching Stages of Six Situations in Boost\&Boost Mode

\begin{tabular}{l|c|c|c|c|c}
\hline Situations & Relationship of $\boldsymbol{d}_{\mathbf{1}}$ and $\boldsymbol{d}_{2}$ & I & II & III & IV \\
\hline (a) & $d_{1} \leq 0.5, d_{2} \leq 0.5$ & $\sqrt{ }$ & $\times$ & $\sqrt{ }$ & $\sqrt{ }$ \\
\hline (b) & $d_{1}>0.5, d_{2} \leq 0.5, d_{1}-d_{2}<0.5$ & $\sqrt{ }$ & $\sqrt{ }$ & $\sqrt{ }$ & $\sqrt{ }$ \\
\hline (c) & $d_{1}>0.5, d_{2} \leq 0.5, d_{1}-d_{2} \geq 0.5$ & $\sqrt{ }$ & $\sqrt{ }$ & $\times$ & $\sqrt{ }$ \\
\hline (d) & $d_{1} \leq 0.5, d_{2}>0.5, d_{2}-d_{1}<0.5$ & $\sqrt{ }$ & $\sqrt{ }$ & $\sqrt{ }$ & $\sqrt{ }$ \\
\hline (e) & $d_{1} \leq 0.5, d_{2}>0.5, d_{2}-d_{1} \geq 0.5$ & $\times$ & $\sqrt{ }$ & $\sqrt{ }$ & $\sqrt{ }$ \\
\hline (f) & $d_{1}>0.5, d_{2}>0.5$ & $\sqrt{ }$ & $\sqrt{ }$ & $\sqrt{ }$ & $\times$ \\
\hline & $\left\{\begin{array}{l}\frac{d i_{L i n 1}}{d t}=\frac{V_{i n 1}}{L_{i n}\left(1-k^{2}\right)}+\frac{\left(V_{i n 2}-V_{i n 1}\right) k^{2}}{2 L_{i n}\left(1-k^{2}\right)} \\
\frac{d i_{L i n 2}}{d t}=\frac{V_{i n 2}}{L_{i n}\left(1-k^{2}\right)}+\frac{\left(V_{i n 1}-V_{i n 2}\right) k^{2}}{2 L_{i n}\left(1-k^{2}\right)} \\
\frac{d i_{L o}}{d t}=\frac{\left(V_{i n 1}+V_{i n 2}\right) k^{2}}{2 M\left(1-k^{2}\right)}\end{array}\right.$
\end{tabular}

Stage III $\left(\boldsymbol{t}_{2}-\boldsymbol{t}_{3}\right): Q_{11}$ and $Q_{22}$ are off, $Q_{12}$ and $Q_{21}$ are on, $i_{\text {Lin1 }}$ and $i_{\text {Lo }}$ decrease, $i_{\text {Lin2 }}$ increases, and

$$
\left\{\begin{array}{l}
\frac{d i_{L i n 1}}{d t}=\frac{\left(V_{i n 1}-V_{o}\right)}{L_{i n}\left(1-k^{2}\right)}+\frac{\left(V_{i n 2}-V_{i n 1}+V_{o}\right) k^{2}}{2 L_{i n}\left(1-k^{2}\right)} \\
\frac{d i_{L i n 2}}{d t}=\frac{V_{i n 2}}{L_{i n}\left(1-k^{2}\right)}+\frac{\left(V_{i n 1}-V_{i n 2}-V_{o}\right) k^{2}}{2 L_{i n}\left(1-k^{2}\right)} \\
\frac{d i_{L o}}{d t}=\frac{\left(V_{i n 1}+V_{i n 2}-V_{o}\right) k^{2}}{2 M\left(1-k^{2}\right)}
\end{array}\right.
$$

Stage IV $\left(\boldsymbol{t}_{3}-\boldsymbol{t}_{4}\right): Q_{11}$ and $Q_{21}$ are off, $Q_{12}$ and $Q_{22}$ are on, $i_{\text {Lin1 }}, i_{\text {Lin2 }}$, and $i_{\text {Lo }}$ decrease, and

$$
\left\{\begin{array}{l}
\frac{d i_{L i n 1}}{d t}=\frac{\left(V_{i n 1}-V_{o}\right)}{L_{i n}\left(1-k^{2}\right)}+\frac{\left(V_{i n 2}-V_{i n 1}\right) k^{2}}{2 L_{i n}\left(1-k^{2}\right)} \\
\frac{d i_{L i n 2}}{d t}=\frac{\left(V_{i n 2}-V_{o}\right)}{L_{i n}\left(1-k^{2}\right)}+\frac{\left(V_{i n 1}-V_{i n 2}\right) k^{2}}{2 L_{i n}\left(1-k^{2}\right)} \\
\frac{d i_{L o}}{d t}=\frac{\left(V_{i n 1}+V_{i n 2}-2 V_{o}\right) k^{2}}{2 M\left(1-k^{2}\right)}
\end{array}\right.
$$

According to the operational analysis, $i_{\text {Lin1 }}$ and $i_{\text {Lin2 }}$ increase linearly when the corresponding main switches are on and decrease when the switches are off. Additionally, though $L_{01}$ and $L_{02}$ work as C-L-C type filters along with $C_{\mathrm{m}}$ and $C_{0}, L_{01}$ and $L_{02}$ also receive induced current ripple from inductor coupling.

According to the relationship of $d_{1}$ and $d_{2}$, six possible working situations (a)-(f) exist in the Boost\&Boost mode, and three or four of the aforementioned switching stages may exist in one switching period under different situations, as described in detail in Table I.

2) Boost\&Buck Mode: When $V_{\mathrm{in} 1}>V_{\mathrm{in} 2}$, for example, $Q_{11}$ is kept off while $Q_{21}$ and $Q_{01}$ are working in interleaved mode. The key waveforms as based on the assumption that $d_{2}<0.5$, $d_{3}>0.5, d_{3}-d_{2}<0.5$ are illustrated in Fig. 6(b). As shown in Fig. 6(b), the four switching stages I-IV are defined as follows: (1) stage I, $Q_{01}$ is on and $Q_{21}$ is off; (2) stage II, $Q_{01}$ and $Q_{21}$ are 
TABLE II

Switching Stages of Six Situations in Boost\&Buck Mode

\begin{tabular}{c|c|c|c|c|c}
\hline Situations & Relationship of $\boldsymbol{d}_{\mathbf{2}}$ and $\boldsymbol{d}_{\mathbf{3}}$ & I & II & III & IV \\
\hline (a) & $d_{2} \leq 0.5, d_{3} \leq 0.5$ & $\sqrt{ }$ & $\times$ & $\sqrt{ }$ & $\sqrt{ }$ \\
\hline (b) & $d_{2} \leq 0.5, d_{3}>0.5, d_{3}-d_{2}<0.5$ & $\sqrt{ }$ & $\sqrt{ }$ & $\sqrt{ }$ & $\sqrt{ }$ \\
\hline (c) & $d_{2} \leq 0.5, d_{3}>0.5, d_{3}-d_{2} \geq 0.5$ & $\sqrt{ }$ & $\sqrt{ }$ & $\times$ & $\sqrt{ }$ \\
\hline (d) & $d_{2}>0.5, d_{3} \leq 0.5, d_{2}-d_{3}<0.5$ & $\sqrt{ }$ & $\sqrt{ }$ & $\sqrt{ }$ & $\sqrt{ }$ \\
\hline (e) & $d_{2}>0.5, d_{3} \leq 0.5, d_{2}-d_{3} \geq 0.5$ & $\times$ & $\sqrt{ }$ & $\sqrt{ }$ & $\sqrt{ }$ \\
\hline (f) & $d_{2}>0.5, d_{3}>0.5$ & $\sqrt{ }$ & $\sqrt{ }$ & $\sqrt{ }$ & $\times$ \\
\hline
\end{tabular}

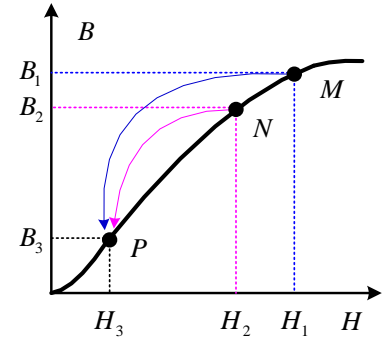

(a)

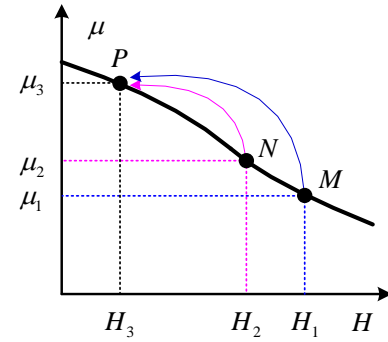

(b)
Fig. 7. Standard magnetization curves of powder magnetic cores. (a) B-H curve. (b) $\mu$-H curve.

on; (3) stage III, $Q_{01}$ is off and $Q_{21}$ is on; (4) stage IV, $Q_{01}$ and $Q_{21}$ are off. According to the relationship of $d_{2}$ and $d_{3}$, six possible situations (a)-(f) exist in the Boost\&Buck mode, and three or four switching stages may exist in each situation, as described in detail in Table II. Similarly, though $L_{\text {in1 }}$ works as a C-L-C type filter along with $C_{\mathrm{in} 1}$ and $C_{\mathrm{m}}, L_{\mathrm{in} 1}$ receives current ripple from inductor coupling.

\section{Characteristics and Design Considerations}

1) DC Flux Reduction: As described in Fig. 4(a), the inductors of the boost cells and buck cell are negatively coupled. In $L_{\mathrm{in} 1}$ and $L_{\mathrm{o} 1}$, for example, the two negative coupled windings charge the magnetic core in opposite ways and the DC flux in the core is greatly reduced. Furthermore, when the coupling tightness of the two windings is increased (coupling coefficient $k$ is increased), DC flux cancellation is increased.

Fig. 7 shows the standard $B-H$ curve and $\mu-H$ curve of powder cores. When the two inductors are individual inductors, the operation points of the cores are $M$ and $N$, respectively. When the inductors are coupled negatively, the final operation point of the core will be $P$, which is close to the initial point and has an increased efficient magnetic permeability value, due to the decreased DC flux. As a beneficial result of the DC flux cancellation of the core, the proposed DIBBC-CI has few magnetic cores and shortened inductor windings, consequently reducing the power loss, size, and weight of the converter.

2) Current Ripple: TEMs are sensitive to the current ripple of converters; hence, a large current ripple will affect the output performance of TEMs. Thus, the current ripples of the input inductors are analyzed as follows.

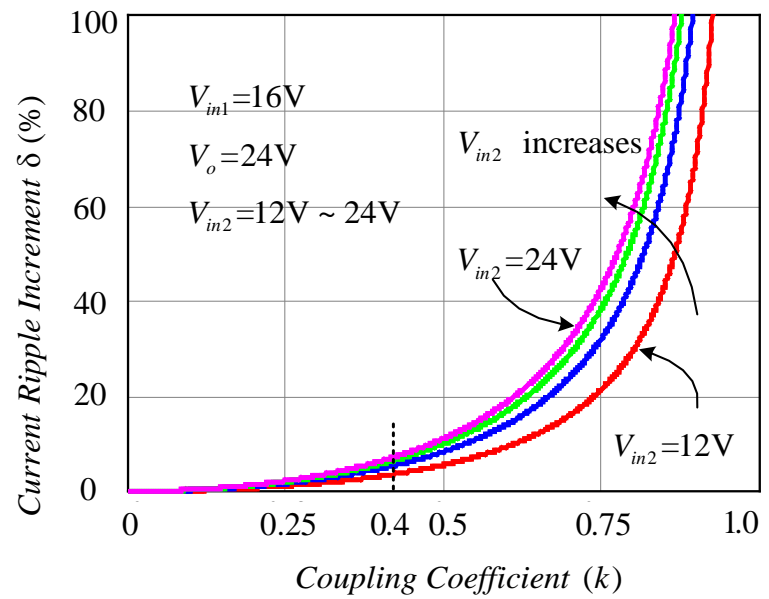

Fig. 8. Curve of inductor current ripple increment versus coupling coefficient $k$.

As an example, we take $L_{\text {in1 }}$ under situation (a) in Boost\&Boost mode as listed in Table I. In accordance with the operational analysis, the current ripple of $L_{\text {in1 }}$ can be obtained as

$$
\Delta i_{L i n 1}=\left[\frac{V_{i n 1}}{L_{i n}}+\frac{\left(V_{i n 1}+V_{i n 2}-V_{o}\right) k^{2}}{2 L_{i n}\left(1-k^{2}\right)}\right] d_{1} T_{s}
$$

Normalized by $V_{\mathrm{in} 1} d_{1} T_{s} / L_{\mathrm{in} 1}$, the per unit value of $\Delta L_{\mathrm{in} 1}$ is

$$
\Delta i_{\text {Lin } 1}^{*}=1+\frac{\left(V_{i n 1}+V_{i n 2}-V_{o}\right)}{2 V_{i n 1}} \cdot \frac{k^{2}}{\left(1-k^{2}\right)}
$$

where the $2^{\text {nd }}$ term, denoted as $\delta$ and described in Eq. (7), represents the increment of the inductor current ripple as compared with the result when $L_{\mathrm{in} 1}$ is an individual inductor.

$$
\delta=\frac{\left(V_{i n 1}+V_{i n 2}-V_{o}\right)}{2 V_{i n 1}} \cdot \frac{k^{2}}{\left(1-k^{2}\right)}
$$

In the condition where DIBBC-CI is working under situation (a) in Boost\&Boost mode, and $V_{\text {in } 1}=16 \mathrm{~V}$ and $V_{\mathrm{o}}=24$ $\mathrm{V}$, when $V_{\text {in2 }}$ changes from $12 \mathrm{~V}$ to $24 \mathrm{~V}$, the relationship of normalized inductor current ripple increment $\delta$ and coupling coefficient $k$ is illustrated in Fig. 8. From Fig. 8, we can conclude that when $k$ is less than $0.4, \delta$ is less than $10 \%$, the increment of current ripple is slight, and the influence on the TEMs can be ignored. However, $\delta$ increases rapidly as $k$ increases, especially when $k$ is near 1 . The normalized increments of $\Delta L_{\mathrm{in} 1}$ under the six situations in Boost\&Boost mode are listed in Table III. The same conclusions can be drawn under the five other situations, indicating that an excessive value of $k$ will greatly increase the input current ripple, which is harmful and undesirable for TEMs.

Therefore, for an optimal coupling coefficient and for well-designed coupled inductors, the counteraction of DC flux and the increment of current ripple should be taken into consideration comprehensively. Appropriate compromise should be made; the coupling coefficient should not be excessively big or small, the preferred value of which is from $0.3-0.4$. 
TABLE III

NORMALIZED INCREMENT OF INDUCTOR CURRENT RIPPLE UNDER Six Situations in Boost\&Boost MODE

\begin{tabular}{c|c}
\hline Situations & Inductor Current Ripple Increment $\boldsymbol{\delta}$ \\
\hline (a) & $\frac{V_{i n 1}+V_{i n 2}-V_{o}}{2 V_{i n 1}} \cdot \frac{k^{2}}{1-k^{2}}$ \\
\hline (b) & $\frac{2\left(V_{i n 1}+V_{i n 2}\right) d_{1}-V_{o}}{4 V_{i n 1} d_{1}} \cdot \frac{k^{2}}{1-k^{2}}$ \\
\hline (c) & $\frac{\left(V_{i n 1}+V_{i n 2}\right) d_{1}-V_{o}\left(d_{1}-d_{2}\right)}{2 V_{i n 1} d_{1}} \cdot \frac{k^{2}}{1-k^{2}}$ \\
\hline (d) & $\frac{\left(V_{i n 1}+V_{i n 2}\right) d_{1}-V_{o}\left(d_{1}-d_{2}+0.5\right)}{2 V_{i n 1} d_{1}} \cdot \frac{k^{2}}{1-k^{2}}$ \\
\hline (e) & $\frac{V_{i n 1}+V_{i n 2}}{2 V_{i n 1} \cdot \frac{k^{2}}{1-k^{2}}}$ \\
\hline (f) & $\frac{2\left(V_{i n 1}+V_{i n 2}\right) d_{1}-V_{o}}{4 V_{i n 1} d_{1}} \cdot \frac{k^{2}}{1-k^{2}}$ \\
\hline
\end{tabular}

Additionally, with consideration for the reflected current ripple due to magnetic coupling, the following principle should be obeyed: the maximum current ripple when an inductor works as a C-L-C filter should be smaller than that when the inductor works as a boost or buck filter inductor.

\section{POWER MANAGEMENT AND CONTROL}

The power management and control strategy proposed for the converter is illustrated in Fig. 9, wherein the following four regulators are employed: input voltage regulators (IVR1, IVR2) for DMPPT of the distributed TEMs, a battery voltage regulator (BVR), and a battery current regulator (BCR) for maximum voltage or maximum current charging control.

A competitive logic is introduced to generate the control voltages, that is, the minimum of the regulator outputs $\left(v_{\mathrm{C} \_I V R 1}, v_{\mathrm{C} \_ \text {IVR2 } 2}, v_{\mathrm{C} \_ \text {BVR }}\right.$ and $\left.v_{\mathrm{C} \_ \text {BCR }}\right)$ is selected to control the corresponding cell. When the battery charging current and voltage is lower than the given maximum value, the following are true: all the power generated from the two TEMs are transferred to the battery, the converter works in the MPPT mode controlled by the IVR, both BVR and BCR will stay in positive saturation, and $v_{\mathrm{C}_{-} \mathrm{BVR}}$ and $v_{\mathrm{C}_{-} \mathrm{BCR}}$ are equal to the positive threshold. Meanwhile, once the battery charging current or voltage reaches its maximum value, the following are true: the battery power is lower than the maximum power that the TEMs can supply, $v_{\mathrm{c} \_ \text {BCR }}$ or $v_{\mathrm{c} \_ \text {BVR }}$ will decrease to replace $v_{\mathrm{C}_{-} I V R}$, and the BCR or BVR will then control the converter instead of the IVR to satisfy the demand of constant current (CC) charging or constant voltage (CV) charging, named CC mode or CV mode, respectively.

The proposed pulse width modulation (PWM) scheme for the converter is given in Fig. 10, wherein $v_{\text {Boost1 }}$ and $v_{\text {Boost2 }}$ are the triangle carrier waves of the two boost cells, whereas $v_{\text {Buck }}$ is that of the buck cell, and the phase shift between $v_{\text {Boost1 }}$ and

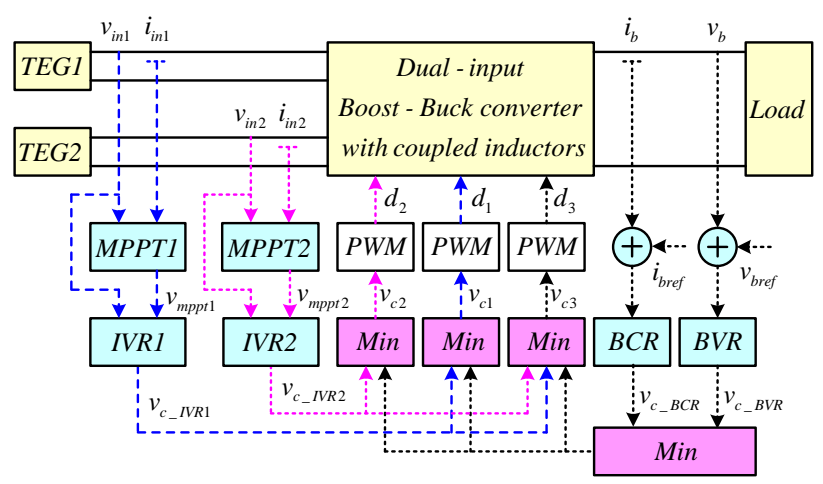

Fig. 9. Block diagram of power control for the converter.

$v_{\text {Boost2 }}$ is $180^{\circ}$. To achieve smooth switching between Boost\&Boost mode and Boost\&Buck mode, we set the valley values of $v_{\text {Boost1 }}$ and $v_{\text {Boost2 }}$ to equal the peak value of $v_{\text {Buck }}$.

We define $v_{\mathrm{c} 1}, v_{\mathrm{c} 2}$, and $v_{\mathrm{c} 3}$ as the control voltages for generating the gate signals of switches $Q_{11}, Q_{21}$, and $Q_{01}$, respectively. According to the aforementioned competitive logic, $v_{\mathrm{c} 1}, v_{\mathrm{c} 2}$, and $v_{\mathrm{c} 3}$ can be selected as

$$
\left\{\begin{aligned}
v_{C 1} & =\min \left(v_{C_{-} I V R 1}, v_{C_{-} B V R}, v_{C_{-} B C R}\right) \\
v_{C 2} & =\min \left(v_{C_{-} I V R 2}, v_{C_{-} B V R}, v_{C_{-} B C R}\right) \\
v_{C 3} & =\min \left(v_{C 1}, v_{C 2}\right) \\
& =\min \left(v_{C_{-} I V R 1}, v_{C_{-} I V R 2}, v_{C_{-} B V R}, v_{C_{-} B C R}\right)
\end{aligned}\right.
$$

If $V_{\text {in } 1}<V_{\text {in2 }}<V_{\mathrm{o}}, 1 \#$ and 2\# boost cells work in the step-up mode, and the duty cycles satisfy $d_{2}<d_{1}$, then $v_{\mathrm{c} 2}<v_{\mathrm{c} 1}, v_{\mathrm{c} 3}=$ $v_{\mathrm{c} 2} \cdot Q_{\mathrm{o} 1}$ is kept on because $v_{\mathrm{c} 3}$ is always higher than $v_{\mathrm{Buck}}$, as shown in Fig. 10(a).

If $V_{\text {in2 }}<V_{\mathrm{o}}<V_{\mathrm{in} 1}, 2 \#$ boost cell works in the step-up mode, and the buck cell works in the step-down mode, then $v_{\mathrm{c} 1}<v_{\mathrm{c} 2}$ and $v_{\mathrm{c} 3}=v_{\mathrm{c} 1}$. $Q_{11}$ is kept off because $v_{\mathrm{c} 1}$ is always lower than $v_{\text {Boost1 }}$, as shown in Fig. 10(b).

With the proposed control and PWM strategy analyzed, automatic control mode transitions between the MPPT mode, CC mode, and CV mode can be achieved. Furthermore, when the relationship of the input voltages, $V_{\mathrm{in} 1}$ and $V_{\mathrm{in} 2}$, and the output voltage, $V_{0}$, changes, a smooth working mode switch between the Boost\&Boost mode and the Boost\&Buck mode can also be obtained automatically.

\section{SimUlation RESUlTS}

The DIBBC-CI shown in Fig. 4(a) is modeled and simulated using PSIM software to verify the feasibility of the proposed topology and control strategy. The TEMs and the load are modeled using a voltage source and a resistor connected in series, respectively. The parameters of the coupled inductors are $L_{\mathrm{in} 1}=L_{\mathrm{in} 2}=22 \mu \mathrm{H}, L_{\mathrm{o} 1}=L_{\mathrm{o} 2}=5 \mu \mathrm{H}, k=0.3$.

Fig. 11 shows the steady-state waveforms in different modes. In Fig. 11(a), the DIBBC-CI works in Boost\&Boost mode, the two boost cells work in step-up mode, and $Q_{01}$ is kept on. In Fig. 11(b), the DIBBC-CI works in Boost\&Buck mode, 2\# boost cell works in step-up mode, the buck cell is 

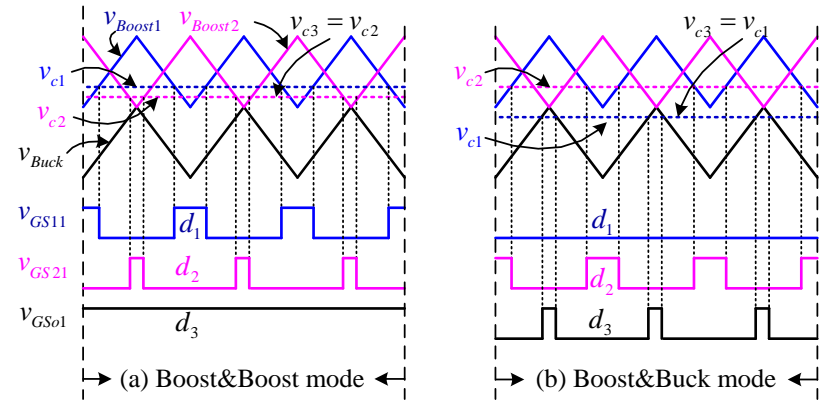

Fig. 10. PWM scheme of the converter.

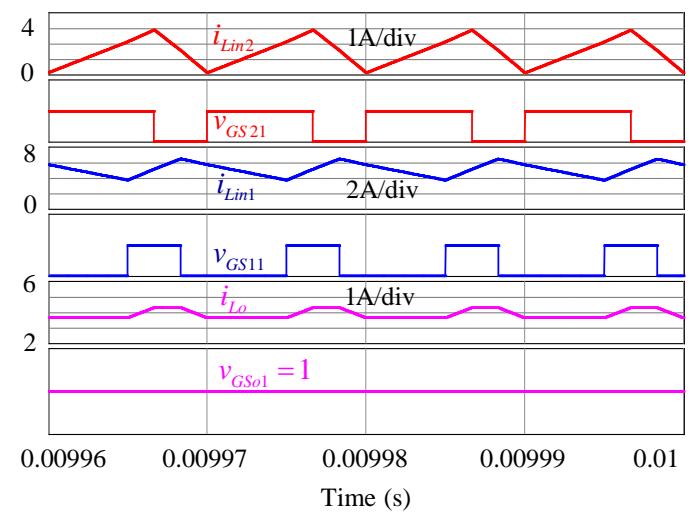

(a)

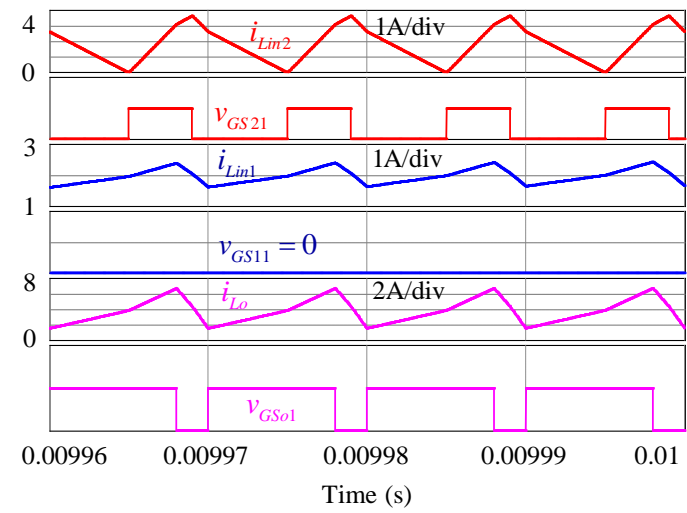

(b)

Fig. 11. Simulation results of the steady-state waveforms. (a) Boost\&Boost mode, 1\#, 2\# boost cells work. (b) Boost\&Buck mode, $2 \#$ boost cell and buck cell work.

working in step-down mode, and $Q_{11}$ is kept off.

Fig. 12 shows the comparison of the current ripples of the two solutions; individual inductors and coupled inductors under the Boost\&Boost mode. As shown in Fig. 12, when $L_{\text {in1 }}$ and $L_{\text {in2 }}$ are coupled inductors, the current ripples are slightly larger than that when $L_{\text {in1 }}$ and $L_{\text {in2 }}$ are independent, but the differences are slight and can be ignored. Meanwhile, as shown in Fig. 11(b), when $L_{0}$ works as a C-L-C filter inductor, the current ripple is smaller than that when $L_{0}$ works as a buck filter inductor.

These steady-state switching waveforms under different modes match the analysis well, verifying the working principle of the proposed topology.

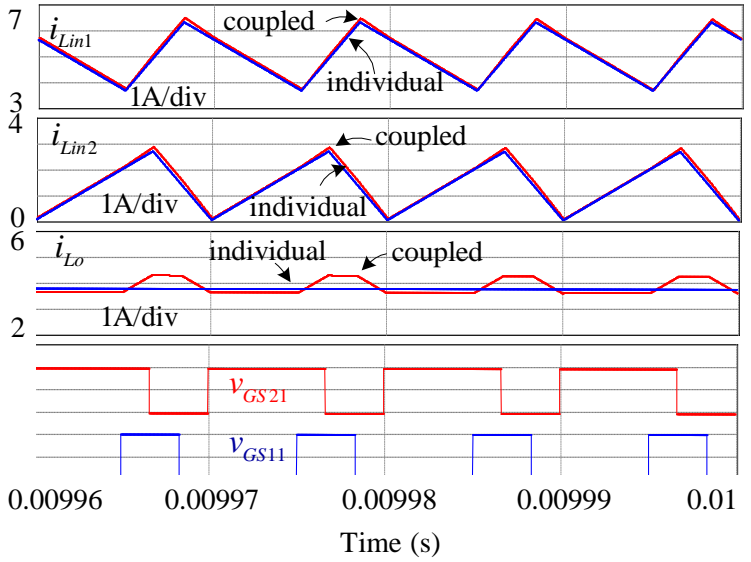

Fig. 12. Comparison of the current ripples of the two solutions: individual inductors and coupled inductors proposed.

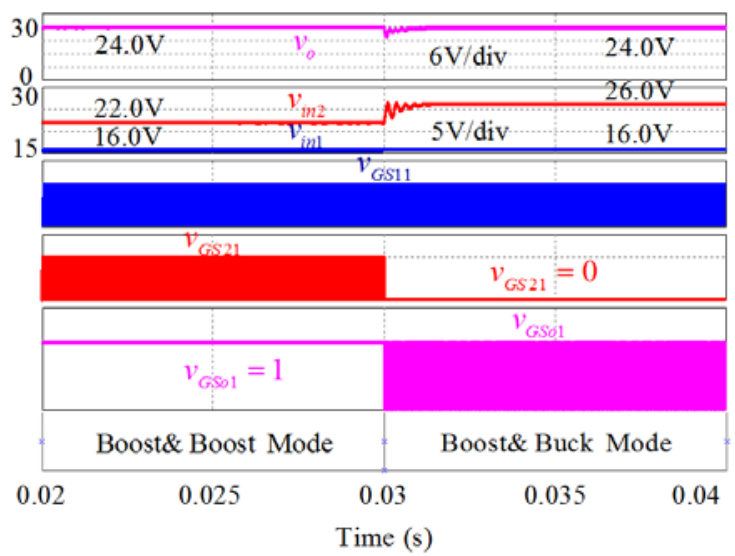

Fig. 13. Simulation results of working mode transition from Boost\&Boost mode to Boost\&Buck mode.

Fig. 13 shows the dynamic transition waveforms from Boost\&Boost mode to Boost\&Buck mode when $V_{\text {in2 }}$ changes. In this case, $V_{\text {in1 }}=16 \mathrm{~V}$ and $V_{\mathrm{o}}=24 \mathrm{~V}$, and $V_{\text {in2 }}$ steps up from $22 \mathrm{~V}$ to $26 \mathrm{~V}$. As shown in Fig. 13, before $V_{\text {in2 }}$ changes, both $V_{\text {in1 }}$ and $V_{\text {in2 }}$ are smaller than $V_{\mathrm{o}}$ and the DIBBC-CI works in the Boost\&Boost mode. After $V_{\text {in2 }}$ increases, $V_{\text {in2 }}$ is bigger than $V_{0}, Q_{21}$ is kept off, 1 \# boost cell works in step-up mode, the buck cell works in step-down mode, and the DIBBC-CI works in the Boost\&Buck mode. When the input voltage changes, smooth switching between different working modes is achieved.

Fig. 14 illustrates the dynamic transition waveforms from MPPT mode to CV mode when the output power changes. In this case, the open-circuit voltages of the DC sources are set as $V_{1}=20 \mathrm{~V}$ and $V_{2}=30 \mathrm{~V}$ and the inner resistors are both $1 \Omega$. The output power is changed by an adjustment in the output resistor. As shown in Fig. 14, before the output resistor changes, both the TEMs are working at the maximum power point. When the output resistor increases, the desired output power is reduced and the output voltage increases to the maximum value. When the output power changes, free switching between different control modes is achieved. 


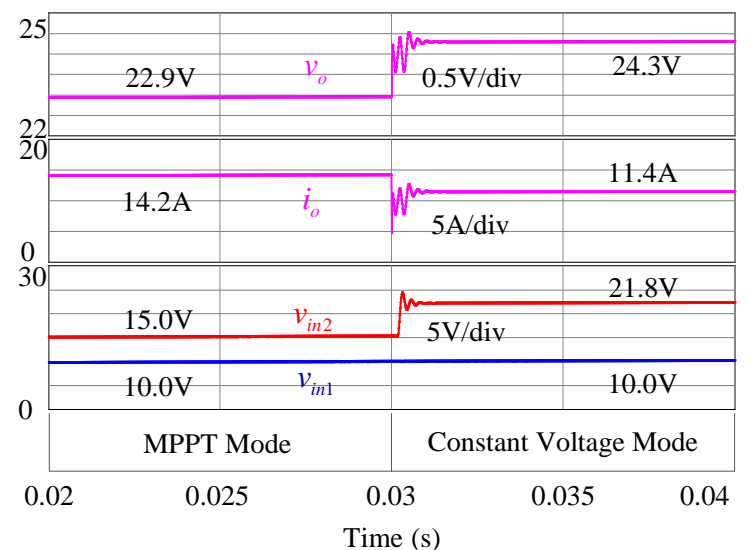

Fig. 14. Simulation results of control mode transition from MPPT mode to CV mode.

TABLE IV

PROTOTYPE PARAMETERS

\begin{tabular}{c|c|c|c}
\hline \hline$v_{\text {in }}$ & $8 \mathrm{~V}-32 \mathrm{~V}$ & $v_{0}$ & $24 \mathrm{~V}$ \\
\hline$L_{\text {in } 1}$, & $21.9 \mu \mathrm{H}$ & $L_{01}, L_{02}$ & $5.0 \mu \mathrm{H}$ \\
$L_{\text {in2 }}$ & KS130-060A & KS106-060A \\
\hline$k$ & 0.3 & Switches & IPP084N06L3G \\
\hline DSP & TMS320F2808 & Switching frequency & $100 \mathrm{kHz}$ \\
\hline \hline
\end{tabular}

TABLE V

COMPARISON OF THE SIZE AND NUMBERS OF INDUCTOR CORES

\begin{tabular}{c|c|c}
\hline \hline & Individual inductors & Coupled inductors \\
\hline \multirow{2}{*}{$L_{\text {in1 }}, L_{\text {in2 }}$} & 4 cores, & 2 cores, \\
& $33 \mathrm{~mm}(\Phi) \times 11 \mathrm{~mm}(\mathrm{~h})$ & $33 \mathrm{~mm}(\Phi) \times 11 \mathrm{~mm}(\mathrm{~h})$ \\
\hline \multirow{2}{*}{$L_{\mathrm{o}}$} & 1 core, & 2 cores, \\
& $27 \mathrm{~mm}(\Phi) \times 11 \mathrm{~mm}(\mathrm{~h})$ & $27 \mathrm{~mm}(\Phi) \times 11 \mathrm{~mm}(\mathrm{~h})$ \\
\hline \hline
\end{tabular}

The results of the dynamic mode transition simulations verify the feasibility of the proposed power management and control strategy.

\section{EXPERIMENTAL RESULTS}

A 450-W DIBBC-CI prototype is built and tested for distributed TEG applications. The key parameters are given in Table IV.

Pictures of the inductors in the proposed coupling and individual solutions are compared in Fig. 15. A comparison of the size and numbers of the inductor cores is presented in Table V. With the negative-coupling, only one core can fit the inductance of $L_{\text {in1 }}$ and $L_{\text {in2 }}$, benefiting from the low DC flux as analyzed; however, with a large DC flux, two cores have to be used individually.

The much decreased DC flux from negative coupling results to lower core-loss. In the proposed coupling solution, the conduction loss in $L_{\mathrm{in} 1}$ and $L_{\mathrm{in} 2}$ is reduced from the shorter length of the windings with only one core than from that of the windings with two cores (Fig. 15). As a result, the total power loss in the inductors is reduced, which is helpful for thermal distribution and reliability.

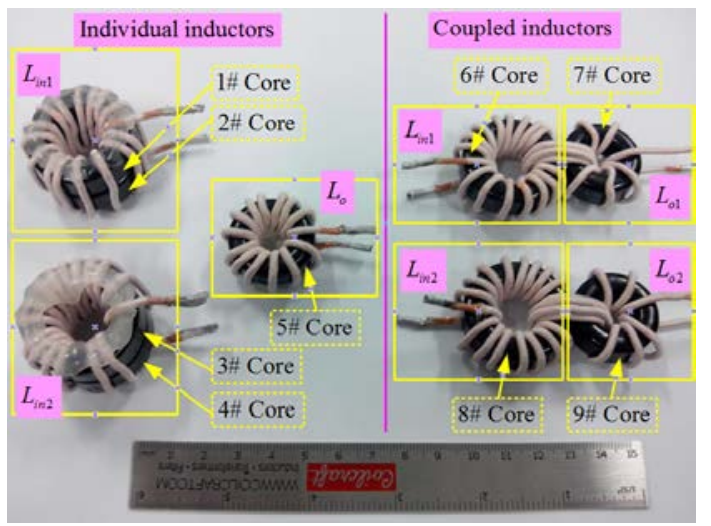

Fig. 15. The inductors of the two solutions: individual inductors and coupled inductors.

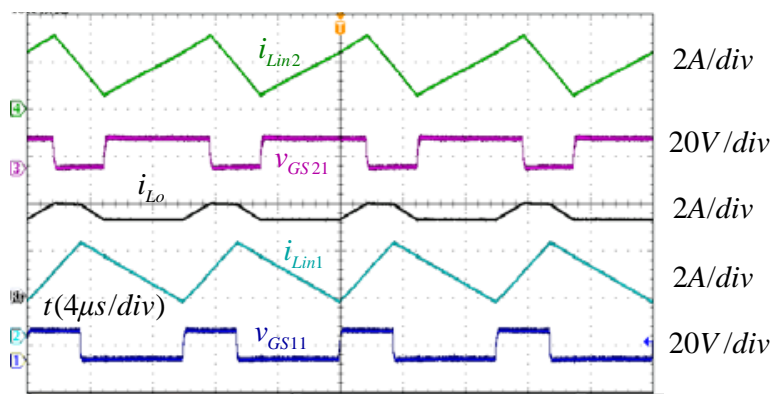

(a)

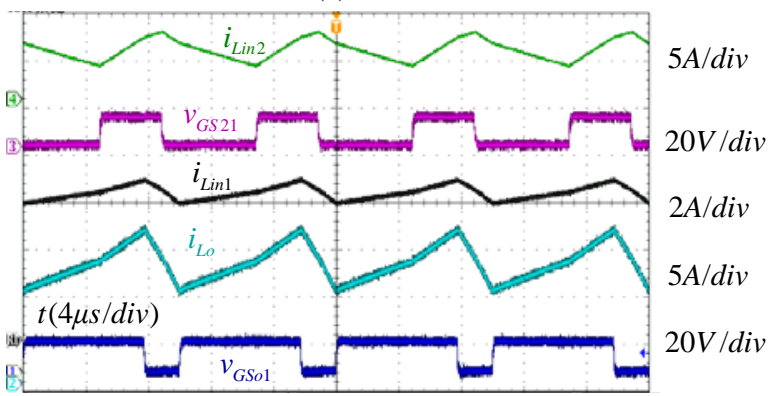

(b)

Fig. 16. Steady-state waveforms. (a) Boost\&Boost mode, 1\#, 2\# Boost cells work. (b) Boost\&Buck mode, 2\# Boost cell and buck cell work.

Fig. 16 shows the steady-state experimental waveforms of the DIBBC-CI under different working modes. In Boost\&Boost mode, $1 \#$ and $2 \#$ boost cells are working in step-up mode and $Q_{01}$ is kept on. In Boost\&Buck mode, $Q_{11}$ is kept off, 2\# boost cell is working in step-up mode, and the buck cell works in step-down mode. As shown in Figs. 6 and 11 , the steady-state switching waveforms match the analysis and simulation results well.

Fig. 17 shows the dynamic waveforms when the load steps in MPPT mode. When the output load resistors step up and down, the input voltages ( $v_{\text {in } 1}$ and $v_{\text {in2 } 2}$ ) stay constant, and all power generated from the TEMs can be delivered to the load.

Fig. 18 shows the waveforms when the working mode is switched between the Boost\&Boost and Boost\&Buck mode as the input voltage changes. When $V_{\mathrm{in} 1}=16 \mathrm{~V}$ and $V_{\mathrm{o}}=24 \mathrm{~V}$, 


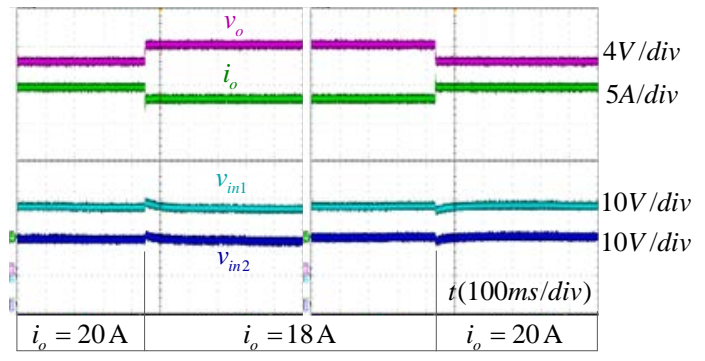

Fig. 17. Waveforms when output load changes in MPPT mode.

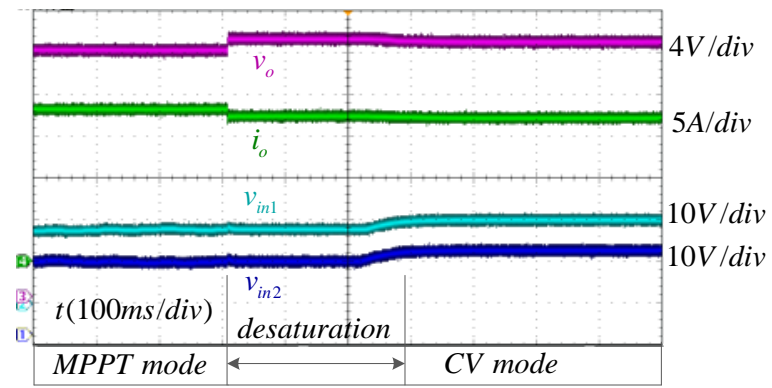

(a)

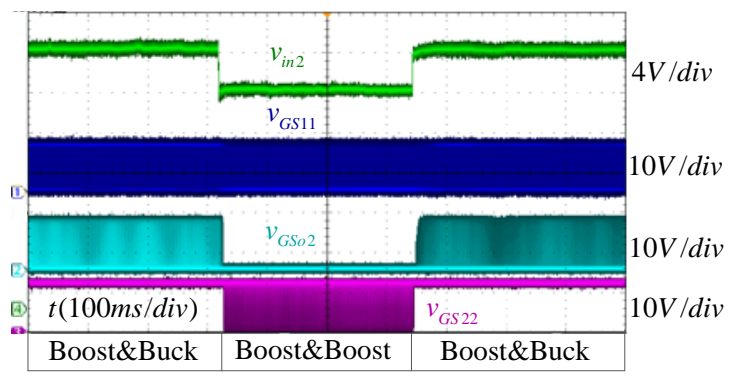

Fig. 18. Working mode transition between Boost\&Buck mode and Boost\&Boost mode.

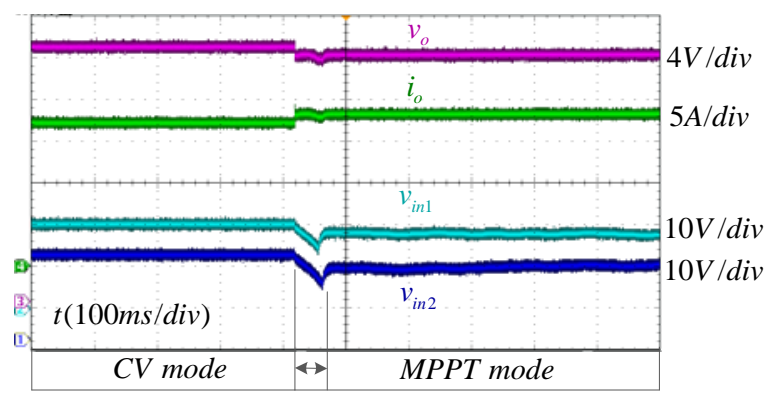

(b)

Fig. 19. Waveforms of operation mode transition between MPPT and CV mode: (a) from MPPT to CV; and (b) from CV to MPPT.

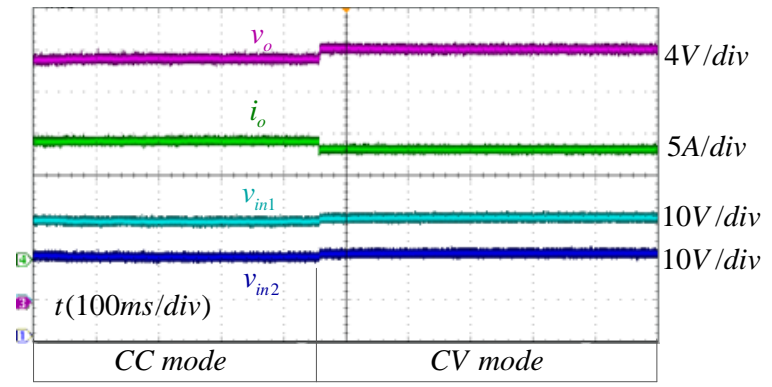

(a)

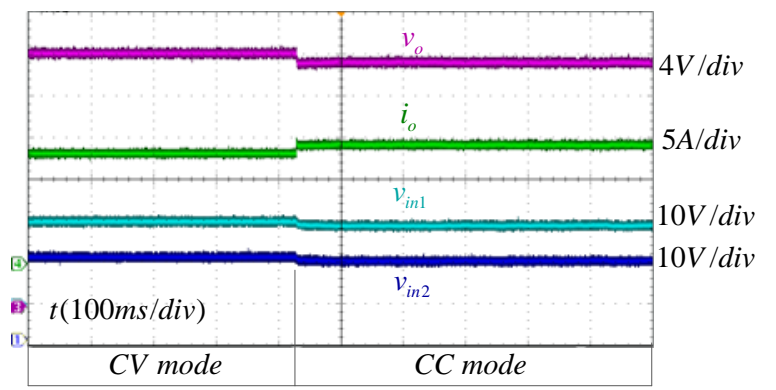

(b)

Fig. 20. Waveforms of operation mode transition between CC mode and CV mode: (a) from CC to CV; and (b) from CV to CC.

and $V_{\text {in2 }}$ transits between $22 \mathrm{~V}$ and $26 \mathrm{~V}$, the converter smoothly switches the working mode.

The DIBBC-CI was tested with a resistance load to verify the mode transitions between different working modes. Fig. 19 illustrates the waveforms when the working mode changes between the MPPT mode and CV mode. As shown in Fig. 19(a), when $v_{0}$ is lower than the command value of $24 \mathrm{~V}$, the converter operates in MPPT mode. After the load resistance is increased, the desired output power is reduced, $v_{0}$ reaches $24 \mathrm{~V}$, and the converter switches to the CV mode. As shown in Fig. 19(b), when the load resistance is decreased, the converter returns to the MPPT mode. Fig. 20 shows the waveforms when the working mode changes between the CC mode and CV mode. The set values of the output voltage and current are $24 \mathrm{~V}$ and $15 \mathrm{~A}$, respectively.

The experimental results of the working mode transitions verify the feasibility of the proposed power management and

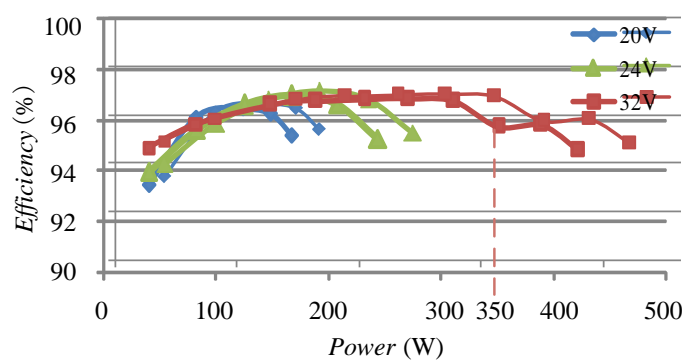

Fig. 21. Tested efficiency.

control strategies described in Figs. 9 and 10.

The efficiencies of the DIBBC-CI are tested using a WT1800 power analyzer with the two inputs connecting to one source (Fig. 21). The efficiency is high over a wide power and input voltage range. Under the input voltage of 32 $\mathrm{V}$, maximum efficiency is at $96.8 \%$; efficiency under full load is at $94.8 \%$. The DIBBC-CI works in buck mode (i.e., 
only the buck cell works) under $350 \mathrm{~W}$; meanwhile, it works in Boost mode (i.e., 1\#, 2\# boost cells work) above $350 \mathrm{~W}$. Under the input voltages of $20 \mathrm{~V}$ and $24 \mathrm{~V}$, the two boost cells work in step-up mode with a maximum efficiency of $96.4 \%$ ( a decrease in voltage translates to a decrease in maximum power - an outward characteristic of TEM).

\section{CONCLUSION}

The proposed novel DIBBC-CI, which can achieve step-up/-down power conversion with low current ripple in both input and output sides, is suitable for distributed TEG applications. The number of the magnetic cores and size of converter are reduced, as benefited from the DC flux cancellation of the coupled inductors, leading to improved power efficiency and density. With the proposed power management and PWM strategy, the converter switches among different operational modes freely and seamlessly. Both the theoretical and the simulation and experimental results verify that the proposed converter operates under a low current ripple, which is critical in distributed TEG applications. The proposed principles can also be applied in multiple-input boost-buck converters where front boost cells can be connected in parallel or in series.

\section{ACKNOWLEDGMENT}

This work was sponsored by the National Natural Science Foundation of China (51377083), the Foundation of the Jiangsu Key Laboratory of New Energy Generation and Power Conversion (ZAB11002), the Industry-Academic Joint Technological Innovations Fund Project of Jiangsu (BY2014003-12), the Beijing Higher Education Young Elite Teacher Project (YETP0097), and the State Key Lab of Power Systems (SKLD14M01).

\section{REFERENCES}

[1] R.-Y. Kim and J.-S. Lai, “Aggregated modeling and control of a boostbuck cascade converter for maximum power point tracking of a thermoelectric generator," in Proc. IEEE APEC, pp. 1754-1760, 2008.

[2] R.-Y. Kim and J.-S. Lai, "A seamless mode transfer maximum power point tracking controller for thermoelectric generator applications," in Proc. IEEE IAS, pp. 977-984, 2007.

[3] Y. Fan, L. Ge, and W. Hua, "Multiple-input DC-DC converter for the thermoelectric-photovoltaic energy system in hybrid electric vehicles," in Proc. IEEE VPPC, pp. 1-5, 2010.

[4] N. Smith and R. McCann, "Investigation of a multiple input converter for grid connected thermoelectric photovoltaic hybrid system," in Proc. IEEE Green Technologies Conference, pp. 1-5, 2012.

[5] J.-S. Choi, J.-S. Ko, and D.-H. Chung, "Development of a thermoelectric cooling system for a high efficiency BIPV module," Journal of Power Electronics, Vol. 10, No. 2, pp. 187-193, Mar, 2010.
[6] D. J. Anderson, J. Sankovic, D. Wilt, D. A. Rebort, and J.-P. Fleurial, "NASA's advanced radioisotope power conversion technology development status," in Proc. IEEE Aerospace Conference, pp. 1-20, 2007.

[7] H. Nagayoshi, K. Tokumisu, and T. Kajikawa, "Evaluation of multi MPPT thermoelectric generator system," in Proc. IEEE ICT, pp. 318 -321, 2011.

[8] D. Cao and F. Peng, "Multiphase multilevel modular DC-DC converter for high current high gain TEG application,” IEEE Trans. Ind. Appl., Vol. 47, No. 2, pp. 1400-1408, May 2011.

[9] S. Bae and A. Kwasinski, "Maximum power point tracker for a multiple-input Ćuk dc-dc converter," in Proc. ITEC, pp. 1-5, 2009.

[10] H. Matsuo, W. Lin, F. Kurokawa, T. Shigemizu, and N. Watanabe, "Characteristics of the multiple-input DC-DC converter,” IEEE Trans. Ind. Electron., Vol. 51, No. 3, 625-631, Jun. 2004.

[11] B. G. Dobbs and P. L. Chapman, "A multiple-input dc-dc converter topology," IEEE Power Electron. Lett., Vol.1, No.1, pp. 6-9, Mar, 2003.

[12] R. Zhao and A. Kwasinski, "Multiple-input single ended primary inductor converter (SEPIC) converter for distributed generation applications," in Proc. IEEE ECCE, pp. 1847-1854, 2009.

[13] O. C. Onar, O. H. A. Shirazi, and A. Khaligh, "Grid Interaction of a Telecommunications Power System With a Novel Topology for Multiple-Input buck-boost Converter,” IEEE Trans. Power Del., Vol. 25, No. 4, pp. 2633-2645, Oct. 2010.

[14] H. Wu, K. Sun, J. Zhang, and Y. Xing, “A TEG efficiency booster with buck-boost conversion,” Journal of Electronic Materials, Vol.42, No.7, pp. 1737-1744, Jul. 2013.

[15] C. Restrepo, J. Calvente, A. Romero, E. V.-Idiarte, and R. Giral, "Current mode control of a coupled-inductor buck-boost dc-dc switching converter,” IEEE Trans. Power Electron., Vol. 27, No. 5, pp. 2536-2549, May 2012.

[16] J. Calvente, L. Martínez-Salamero, P. Garcés, R. Leyva, and A. Capel, "Dynamic optimization of bidirectional topologies for battery charge/discharge in satellites," in Proc. IEEE PESC, pp. 1994-1999, 2001.

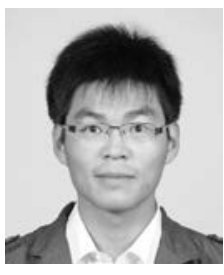

Junjun Zhang was born in Jiangsu Province, China, in 1986. He received his B.S. degree in electrical engineering from Nanjing University of Aeronautics and Astronautics (NUAA), Nanjing, China, in 2010. He is currently working toward a Ph.D. degree in electrical engineering at NUAA. His main research interests include topology and control of power converters, distributed power generation, and spacecraft power systems.

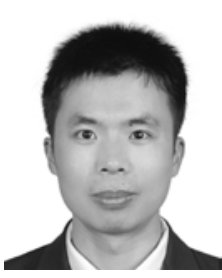

Hongfei Wu was born in Hebei Province, China, in 1985. He received his B.S. and Ph. D degrees in electrical engineering in 2008 and 2013, respectively, from Nanjing University of Aeronautics and Astronautics (NUAA), Nanjing, China. Between June 2012 and July 2012, he was a guest PhD student at the Institute of Energy Technology, Aalborg University, Denmark. Since 2013, he has been with the Faculty of Electrical Engineering, NUAA, and is currently an Associate Professor with the College of Automation Engineering, NUAA. He has authored and coauthored more than 90 technical 
papers published in journals and conference proceedings. His research interests include power converters, distributed power generation, and spacecraft power systems.

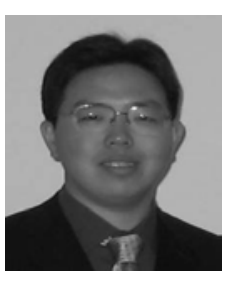

Kai Sun received his B.E., M.E., and Ph.D. degrees in electrical engineering, in 2000, 2002, and 2006, respectively, from Tsinghua University, Beijing, China. In 2006, he joined the faculty of Electrical Engineering, Tsinghua University, and is currently an Associate Professor. Between September 2009 and August 2010, he was a visiting scholar of the Electrical Engineering at Department of Energy Technology, Aalborg University, Denmark. His research interests are power electronics for renewable generation systems and microgrids and application techniques of power devices. He is a member of the IEEE IES Renewable Energy Systems Technical Committee and of the IEEE PELS Technical Committee of Sustainable Energy Systems. Dr. Sun received the Delta Young Scholar Award in 2013.

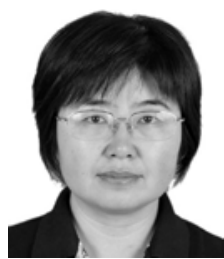

Yan Xing was born in Shandong Province, China, in 1964. She received her B.S. and M.S. degrees in automation and electrical engineering in 1985 and 1988, respectively, from Tsinghua University, Beijing, China. Her Ph.D. degree in electrical engineering, she received from Nanjing University of Aeronautics and Astronautics (NUAA), Nanjing, China, in 2000. Since 1988, she has been with the Faculty of Electrical Engineering, NUAA, and is currently a professor for the College of Automation Engineering, NUAA. She has authored more than 100 technical papers published in journals and conference proceedings and has also published three books. Her research interests include topology and control for DC-DC and DC-AC converters.

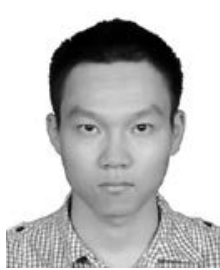

Feng Cao was born in Hunan Province, China, in 1989. He received his B.S. and M.S degrees in electrical engineering in 2011 and 2014, respectively, from Nanjing University of Aeronautics and Astronautics (NUAA), Nanjing, China. His main research interests include topology and control of power converters. 